\title{
Amyotrophic Lateral Sclerosis Presenting as Chronic Cough
}

Marjorie Friedman, MD

\section{INTRODUCTION}

Amyotrophic Lateral Sclerosis (ALS) is a debilitating, uniformly fatal disease. While it most commonly presents with limb weakness, patients may also present with neurocognitive, respiratory, or bulbar symptoms. Despite its poor prognosis, an early diagnosis can save patients from unnecessary and expensive testing, lead to interventions that improve quality of life, and give patients and family time for advanced planning. ${ }^{1}$ This case highlights an unusual presentation of ALS.

\section{CASE PRESENTATION}

A 77-year-old male with a past medical history of coronary artery disease, three-vessel coronary artery bypass graft surgery, mild chronic obstructive pulmonary disease (COPD) and a 40 pack year cigarette smoking history presented with a chief complaint of cough which began in March 2016. His only other complaint was mild dyspnea on exertion. He was treated twice with oral steroids and antibiotics as an outpatient for COPD exacerbations without improvement. In August 2016, he saw a new pulmonologistfor his persistentcough. The pulmonologist obtained a chest xray and pulmonary function tests (PFTs) (Table 1), and adjusted his medications. The chest xray showed a left hemidiaphragm elevation but was otherwise unremarkable. A follow up fluoroscopic sniff test showed no evidence of paradoxical motion.

He initially presented to the hospital in October 2016, and complained of coughing fits and progressive dyspnea on exertion. His cough was productive of yellow sputum and worse with lying flat. He also complained that his voice had a new nasal quality. He denied heartburn, dyspepsia, post nasal drip, lower extremity edema or chest pain. His vital signs were within normal limits and he appeared well. Cardiac exam was normal. He had scattered expiratory wheezes and no clubbing. Admission labs are listed in Table 2.

\section{DIFFERENTIAL DIAGNOSIS}

The patient's chief complaint was a chronic cough. The patient did have a history of smoking, a diagnosis of COPD, and ACE inhibitor use, all of which are commonly associated with cough. Excluding these risk factors, the most common causes of chronic cough are upper
Table 1: PFTs from September 2016

\begin{tabular}{|c|c|c|}
\hline & $\begin{array}{c}\% \\
\text { Predicted }\end{array}$ & $\begin{array}{c}\% \text { Predicted: } \\
\text { After bronchodilator } \\
\text { challenge }\end{array}$ \\
\hline $\mathrm{FEV} 1 / \mathrm{FVC}$ & $111 \%$ & $110 \%$ \\
\hline $\mathrm{FEV} 1$ & $52 \%$ & $57 \%$ \\
\hline $\mathrm{TLC}$ & $45 \%$ & \\
\hline $\mathrm{RV}$ & $36 \%$ & \\
\hline $\mathrm{DLCO}$ & $68 \%$ & \\
\hline $\begin{array}{c}\mathrm{DLCO} / \mathrm{NA} \\
\text { (corrects for alveolar } \\
\text { volume) }\end{array}$ & $133 \%$ & \\
\hline
\end{tabular}

Table 2: The Patient's Admission Labs

\begin{tabular}{|c|c|c|}
\hline & Patient Result & Normal Value Range \\
\hline WBC & $9.7 \mathrm{~B} / \mathrm{L}$ & $4-11 \mathrm{~B} / \mathrm{L}$ \\
\hline Hgb & $14.6 \mathrm{~g} / \mathrm{dL}$ & $14.0-17.0 \mathrm{~g} / \mathrm{dL}$ \\
\hline Platelets & $193 \mathrm{~B} / \mathrm{L}$ & $140-400 \mathrm{~B} / \mathrm{L}$ \\
\hline Creatinine & $1.3 \mathrm{mg} / \mathrm{dL}$ & $0.7-1.4 \mathrm{mg} / \mathrm{dL}$ \\
\hline Bicarbonate & $21 \mathrm{mmol} / \mathrm{L}$ & $24-32 \mathrm{mmo} / \mathrm{L}$ \\
\hline Troponin T & $<0.01 \mathrm{ng} / \mathrm{mL}$ & $<0.01 \mathrm{ng} / \mathrm{mL}$ \\
\hline proBNP & $33 \mathrm{pg} / \mathrm{mL}$ & $<450 \mathrm{pg} / \mathrm{mL}$ \\
\hline VBG pH & 7.36 & $7.32-7.43$ \\
\hline VBG CO2 & $59 \mathrm{mmHg}$ & $38-50 \mathrm{mmHg}$ \\
\hline Lactate & $2.2 \mathrm{mmol} / \mathrm{L}$ & $0.5-2.0 \mathrm{mmol} / \mathrm{L}$ \\
\hline TSH & $0.22 \mathrm{ulU} / \mathrm{mL}$ & $0.3-5.0 \mathrm{ulU} / \mathrm{mL}$ \\
\hline Free T4 & $1.1 \mathrm{ng} / \mathrm{dL}$ & $0.7-1.7 \mathrm{ng} / \mathrm{dL}$ \\
\hline
\end{tabular}

airway cough syndrome, asthma, and GERD. ${ }^{2}$ However, the patient's abnormal PFTs provided a starting point for evaluating his symptoms

The patient's PFTs were most notable for restrictive lung physiology: FEV1/FVC ratio was elevated, and TLC was markedly low. The $11 \%$ absolute change in his FEV1 with bronchodilator challenge suggested an element of obstruction as well (close to the cutoff of $12 \%$ generally used). However, given that the FEV1/FVC ratio was elevated and repeated treatments for COPD exacerbations did not relieve his symptoms, it was thought that his presentation was not entirely explained by COPD alone. 
The differential diagnosis for restrictive lung physiology includes interstitial lung disease (ILD), extrinsic disorders that cause chest wall compression such as kyphosis or obesity and neuromuscular disorders. The patient had no evidence of ILD on chest CT. The elevated DLCO/VA on PFTs implied no issues with diffusion of gases across the alveoli membrane which further argued against ILD. The patient was mildly obese with a body mass index of 33, but his habitus was not thought to be sufficient enough to cause extrinsic restriction to the degree seen on his PFTs. The differential diagnosis of neuromuscular disorders that cause restrictive lung disease can be divided into the following categories: spinal cord disease such as multiple sclerosis, motor neuron disease such as amyotrophic lateral sclerosis (ALS), neuromuscular junction disease such as myasthenia gravis and muscle disease such as polymyositis.

\section{OUTCOME AND FOLLOW-UP}

During his initial hospitalization, the patient received nebulizers and a course of steroids and moxifloxacin. Additional laboratory work to evaluate for neuromuscular disorders (arterial blood gas and creatine kinase) was unremarkable. Neurology was consulted but did not consider the patient's history and physical exam concerning for a neuromuscular disease. His symptoms improved and he was discharged.

A week later, he returned to the emergency room complaining of severe dyspnea, wheezing and a persistent cough that woke him from sleep. Although compliant with medications, he experienced little symptomatic relief. He was admitted to the hospital and underwent a transthoracic echo and CT of the sinuses both of which were unremarkable. His symptoms improved within one day and he was again discharged. The patient was referred to otolaryngology as an outpatient who started the patient on a trial of omeprazole for laryngospasm and tramadol for neurogenic cough.

In November 2016, the patient presented again. His symptoms had progressed to the point that he had to sleep upright in a chair and could not catch his breath after walking up a flight of stairs. His initial oxygen saturation was $80 \%$ on room air. He was again treated with nebulizers and antibiotics and admitted for further workup. After several days he was noted to have fasciculations of his hand muscles. An EMG was performed and results were consistent for ALS.

Before discharge, the patient was seen by palliative care for assistance with coping with his diagnosis and advanced care planning. He was discharged home on BiPAP which led to a profound improvement in his sleep, dyspnea, and cough. He continues to follow regularly with Jefferson pulmonology and neurology at the
Jefferson Weinberg ALS Center and has only been admitted to the hospital once since the diagnosis was made.

\section{DISCUSSION}

The average time between onset of symptoms and diagnosis of ALS is 13-18 months. ${ }^{1}$ The majority of ALS cases (70-80\%) present initially with asymmetric limb weakness whereas respiratory symptoms are present in about $5 \%$ of patients and bulbar symptoms (such as hoarse voice and laryngospasm) are present in only about 20\%. ${ }^{3}$ Given the rarity of ALS (incidence of 2:100,000 in western countries), patients tend to undergo treatment of more common conditions prior to diagnosis of ALS as seen in our case. ${ }^{3}$ Also, our patient did not have a classic presentation of ALS which added to the delay in his diagnosis.

In addition to providing a unique presentation of ALS, our patient's case highlights several important features of caring for patients with ALS. Non-invasive positive pressure ventilation (NIPPV) is an important tool that has been shown to improve quality of life and increase survival by an average of 15 months. ${ }^{4}$ Advanced care planning is also crucial for patients diagnosed with ALS and should involve creation of a living will, appointing a power of attorney, and discussions regarding PEG and tracheostomy placement. Continued healthcare at a multidisciplinary center for ALS, which our patient receives, has been shown to lead to better outcomes. ${ }^{1}$

\section{KEY POINTS}

- Our patient presented with chronic cough and restrictive lung disease and after extensive workup was diagnosed with ALS.

- Bulbar and respiratory symptoms are uncommon initial presentations of ALS.

- Early diagnosis of ALS can allow for advanced care planning and help patients initiate treatment earlier which can lead to improved quality of life.

\section{REFERENCES}

1. Anderson PM, Borasio GD, Dengler R, et al. Good practice in the management of amyotrophic lateral sclerosis: Clinical guidelines. An evidence-based review with good practice points. EALSC Working Group. Amyotrophic Lateral Sclerosis. 2007:8:195-213.

2. Kiernan MC, Cheah VS, Turner MR, et al. Amyotrophic lateral sclerosis. Lancet. 2011;377: $942-55$

3. Iyer VN, Lim KG. Chronic Cough: An Update. Mayo Clinic Proceedings. 2013:8:1115-1126

4. Shoesmith CL, Findlater K, Rowe A, et al. Prognosis of amyotrophic lateral sclerosis with respiratory onset. Journal of Neurology, Neurosurgery $\&$ Psychiatry. 2007:78: 629-631 